\title{
Cartilha pedagógica: potências pedagógicas entre visualidades
}

Resumo: O presente trabalho é o resultado de uma reflexão sobre o processo de criação de uma cartilha pedagógica, composta por 07 (sete) fichas com imagens de referência dos/as alunos/as de uma escola da rede pública do Distrito Federal, juntamente com imagens reconhecidas e institucionalizadas do campo da Arte - História da Arte. As fichas contam com 02 (duas) propostas pedagógicas, com questões potentes a partir das imagens, e com dicas de referências de outras visualidades do campo da Arte ou não. Desse modo, os apontamentos teóricos deste trabalho são provenientes dos estudos da Cultura Visual que revelam um discurso pedagógico e sistemático de modo que colocam as visualidades com produtoras se sentidos, discursos, significados e conhecimentos, auxiliando os/as professores/as e arte/educadores em suas práticas pedagógicas cotidianas no trabalho com as imagens. Assim, foi possível estabelecer interfaces e problematizações entre as imagens de referência reconhecidas do universo dos/as alunos/as com as imagens do campo da Arte, tendo como foco os aspectos pedagógicos entre as imagens. 


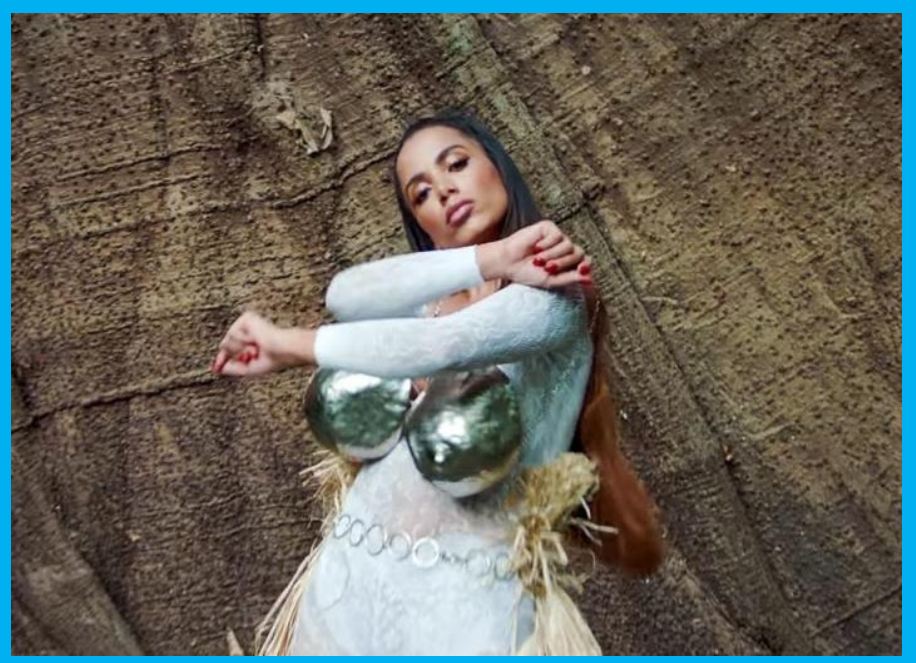

Imagem de Referência: Anitta -

Cantora e compositora Brasileira.

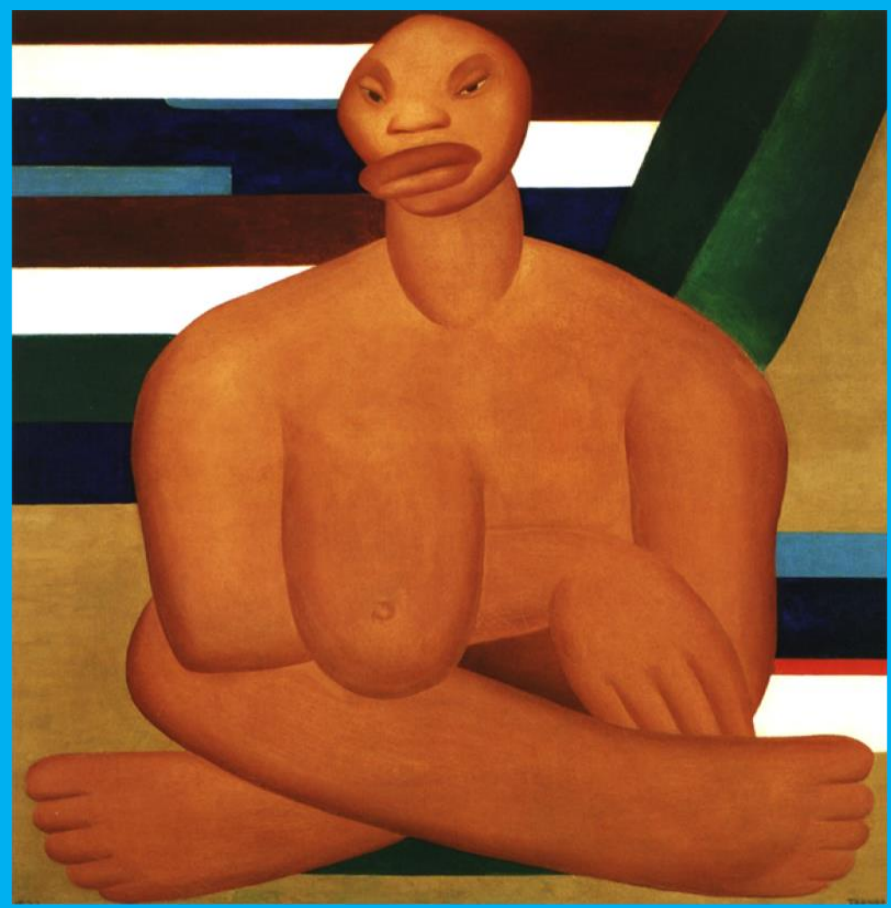

Obra: “A Negra”, 1923.

Tamanho: $100 \mathrm{~cm}$ x $80 \mathrm{~cm}$, Óleo sobre tela.

Localizada em: Museu de Arte Contemporânea - Mac da USP, Brasil.

Artista: Tarsila do Amaral

Dicas de pesquisas: Semana de Arte Moderna de 1922. Escultura da "Vênus de Willendorf". A pintura Expressionista "Duas Mulheres" de 1915, do artista Egon Schile. A Obra "O Nascimento de Vênus" de 1483, do artista Sandro Botticilli. A pintura "Susana e os Velhos" de 1555, de Tintoretto. As pinturas "A Maya despida" de 1797 - 1800 e "Maya vestida" de 1800 - 1805 de Francisco Goya. A fotografia "Dadivosa" de 1999, da artista Brasileira Ariana Varejão. A performance "Peqqy Guggenheim Collection" de 2001 da artista Vanessa Beecorft. A performance "Balkan Erotic Epic" de 2005, da artista Marina Abramovic. As instalações da artista Brasileira Nazareth Pacheco realizadas de giletes. Visualidades da mídia de massa que fazem enfatizam a mulher e ao corpo humano.
Questões Potentes: A cantora Brasileira Anitta, em um de seus trabalhos "Is that for me", explora certa caracterização exagerada e "fantasiosa". Existiria alguma relação com o imaginário visual e social do povo brasileiro? E na obra de Tarsila do Amaral? Existiria, nas duas imagens, certa valorização do Brasil? Quais as diferenças e semelhanças entre as duas imagens? Saberíamos dizer quais seriam os respectivos contextos culturais e sociais nos quais tais produções foram desenvolvidas? Haveria, na imagem de cantora Anitta, alguma referência à cultura africana e indígena? Qual seria? Qual a importância da cultura de matriz africana e indígena para a constituição do povo brasileiro? Seria a intenção de Tarsila do Amaral representar tal importância? Como tais aspectos se apresentam em nossos dias?

Proposta 01: Ao analisar e discutir acerca das imagens apresentadas proponha aos estudantes que produzam esculturas a partir da argila. Proponha a eles que desenvolvam as formas da figura humana tendo em vista suas diversas características e "qualidades". Será interessante perceber que trabalhos dessa natureza são, na perspectiva dos estudantes, um motivo de "brincadeiras" e situações constrangedoras, contudo, será preciso enfatizar o cunho pedagógico e artístico da atividade. Ao desenvolver as formas da figura humana tendo como meio de trabalho a escultura, questões como a "diversidade" e a própria "criatividade" poderão ser trabalhadas. Cabe considerar que a figura humana, em suas diversas representações, sempre esteve atrelada ao contexto em que ela foi produzida. Nesse sentido, explore dos estudantes a intenção e a motivação de suas criações, como por exemplo: "Por que essa 'parte do corpo' se apresentou dessa maneira?" "Ao observar os trabalhos dos colegas, conseguiremos detectar alguma semelhança", "Qual seria a ideia de destacar uma parte do corpo e não outra?" "A representação do corpo humano, construído dessa maneira, existe na realidade?" - Proponha uma discussão crítica sobre os trabalhos.

Proposta 02: Peça para que os estudantes tragam revistas, cola e tesoura. Desse modo, incentive-os a observar os diferentes "corpos" que circulam em meio às páginas das revistas. Em seguida, sugira que os estudantes "desconstruam" as imagens das pessoas, recortando as diferentes imagens que esses corpos apresentam. $O$ interessante é coletar imagens de diferentes tamanhos e perspectivas. Em seguida, monte a imagem de uma nova pessoa, encaixando cada parte do corpo (recortes das páginas da revista) no seu devido lugar. Perceba que tal proposta didática se assemelha a uma atividade artística que remete ao movimento cubista. Assim, pode-se trabalhar aspectos da "diversidade corporal" a qual permeia o universo dos/as estudantes. Sob uma postura quase humorística e caricata dos diferentes "corpos" que foram construídos aspectos primordiais do campo educacional poderão ser trabalhados. 


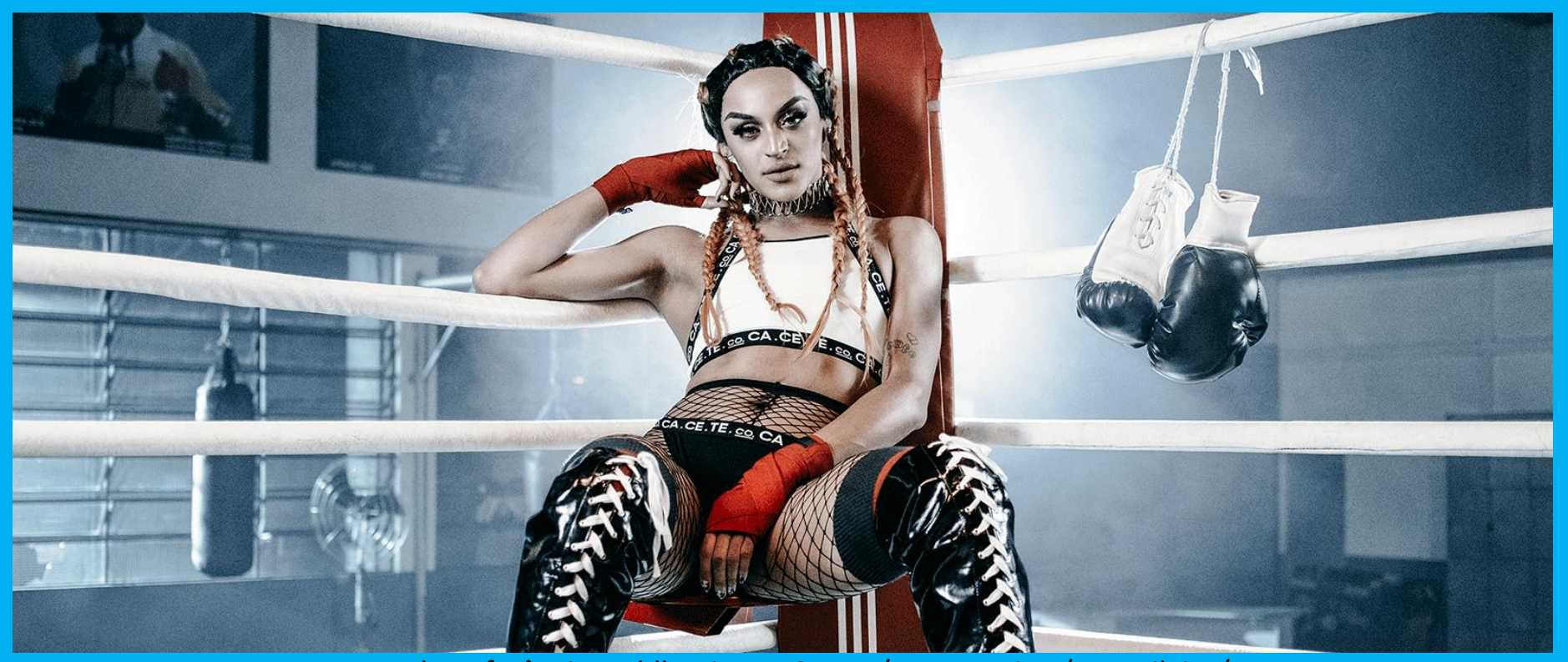

Imagem de Referência: Pabllo Vittar - Cantor/a compositor/a Brasileiro/a

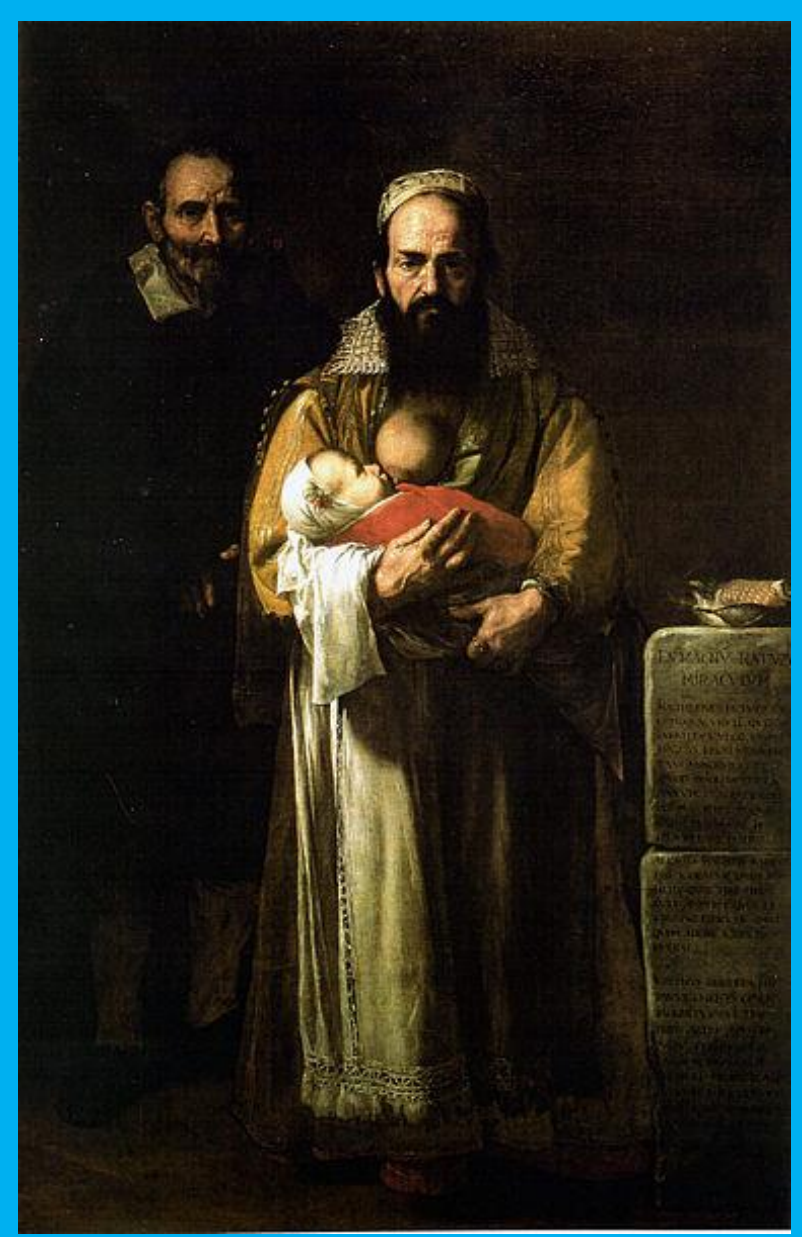

Obra: “Mujer Barbuda”, 1931.

Tamanho: $212 \mathrm{~cm}$ x $144 \mathrm{~cm}$, Óleo sobre tela. Localizada em: Museu da Fundação Lerma - Espanha. Artista: Jusepe de Ribera (1591 - 1652).

Dicas de pesquisas: Fotografias da artista Nan Goldin e Obras de Andy Warhol "Self-portraits in drag". A fotografia de Marcel Duchamp "Rrose Sélavy". Filmes: "A pele que Habito", "Transamérica", "As Sufragistas", "Coco antes de Chanel" e "A Garota Dinamarquesa". Músicas do/a cantor/a Liniker.
Questões Potentes: Qual é a diferença entre as imagens? Quais são as semelhanças entre as imagens? As duas imagens representam a figura feminina? Por que o artista pop Pabllo Vittar está vestido com roupas femininas e a "Mulher Barbuda" com roupas masculinas respectivas da sua época? Pabllo Vittar se veste sempre de mulher? Ele não é uma Drag Queen? E o que é uma Drag Queen? Por que a muIher barbuda, figura da obra de Jusepe de Ribera, está vestida de homem e amamentando uma criança? Em que época ou momento da História foi pintado a obra "A Mulher Barbuda"? Em nossa sociedade, existem roupas e acessórios específicos para homens e para mulheres? As roupas e acessórios que "vestimos" decidem quem somos? Mulheres podem usar roupas de homens, tal como apresenta a obra de Jusepe de Ribera? Na contemporaneidade há uma nova proposta no campo da moda em que homens e mulheres utilizam as mesmas roupas, são as chamadas "roupas sem gênero". Assim, saberíamos identificar quais seriam esses itens? Quais seriam as suas características?

Proposta 01: Peça para os estudantes levem para a sala de aula objetos pessoais, acessórios e roupas de suas preferências e que tenham mais afinidades. Coloque-os em um espaço, de modo que todos possam visualizar e misture todos os itens, uma vez que não se saiba de quem são as peças. Discuta sobre o que trouxeram, se são de homens ou de mulheres, ou se podem ser usados por ambos. Tentem identificar de quem são os objetos/acessórios, discutindo, ao mesmo tempo, sobre o que usamos - cores, tamanhos, formatos, espessuras - sem qualquer influência da nossa identidade de gênero. Peça para os estudantes construam looks para um gênero neutro, a partir dos objetos/acessórios e depois os fotografe.

Proposta 02: Realize com os estudantes uma coleta em revistas e jornais de diferentes imagens de roupas/acessórios e objetos, em que os estudantes julguem ser de gênero neutro. Em seguida, peça que desenvolvam uma colagem, construindo um/uma personagem com os recortes e informações visuais que coletaram. Discuta sobre as produções realizadas, fazendo relações com as imagens aqui problematizadas, e o cotidiano dos estudantes. Pergunte-os se usariam as roupas e por que. 


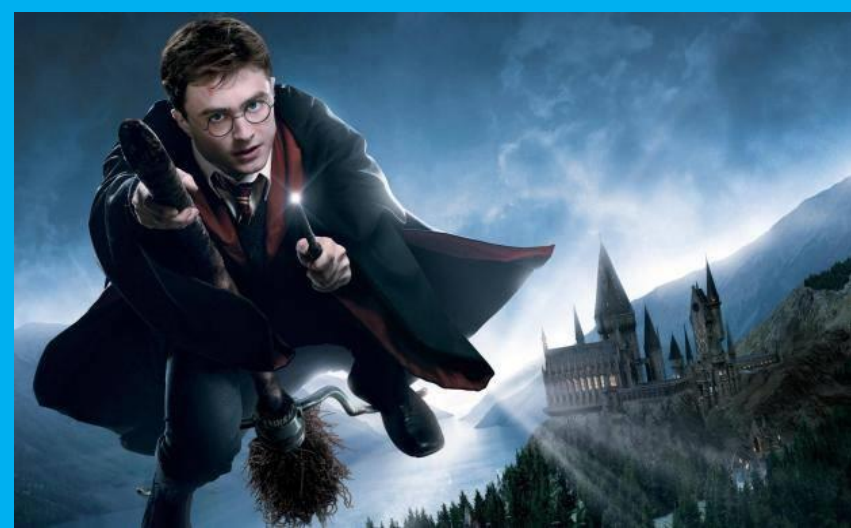

Imagem de Referência: Herry Potter - é uma série de sete Fantasias escrita pela autora Britânica J.K. Rowling.

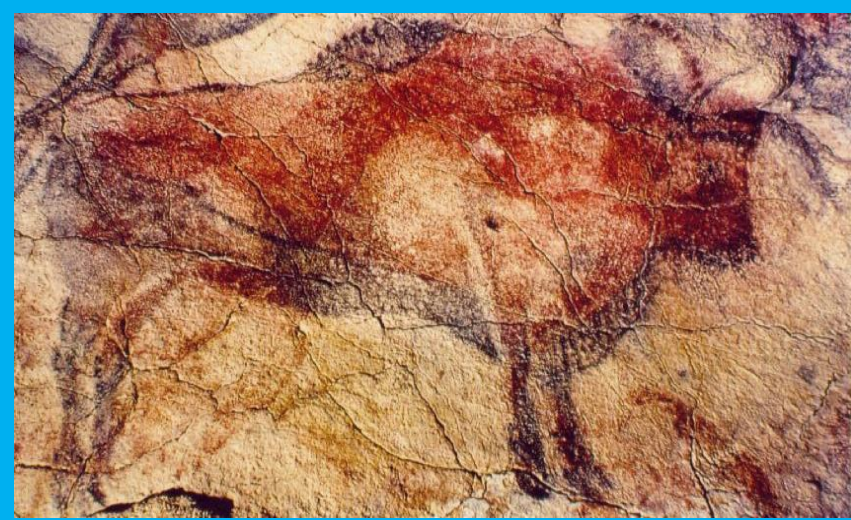

Bisão da Caverna de Altamira, c, 15000 - 12000 a. C.

Espanha.

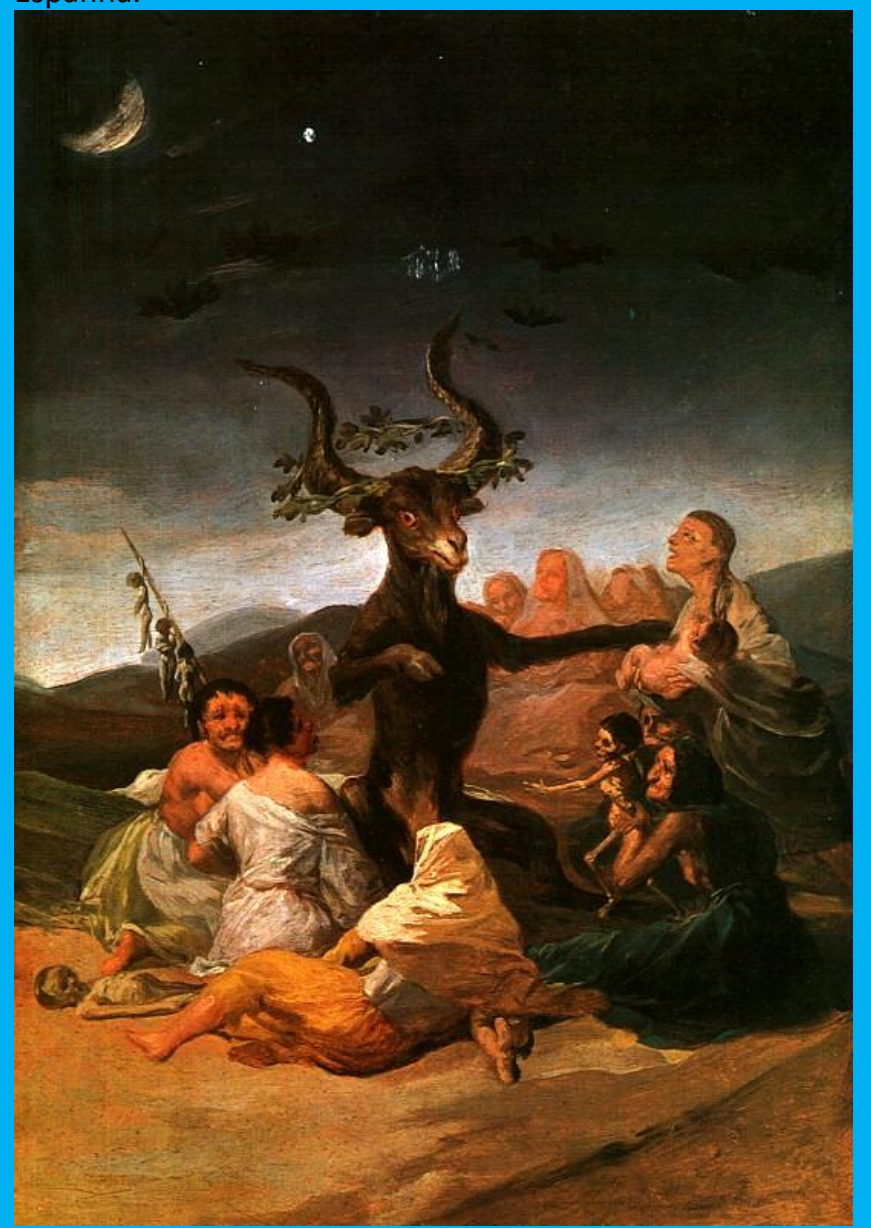

Obra: “O Sabá das Bruxas" ou “El Aquelarre”, 1931.

Tamanho: $43 \mathrm{~cm} \times 30 \mathrm{~cm}$, Óleo sobre tela.

Localizada em: Museu Lázaro Galdiano - Madrid.

Artista: Francisco José de Goya (1746 - 1828).
Questões Potentes: Quais seriam as relações entre essas três imagens? Na perspectiva da História da Arte, os vestígios da caverna da região de Altamira, na Espanha, revelam práticas relacionadas à magia? Em que medida? Qual a diferença entre os filmes de magia/aventura de Harry Potter os "rituais de magia" nas cavernas de Altamira? Nessa perspectiva, o que seria "magia"? Na obra "O Sabá das Bruxas", do artista Goya, que tipo de ritual está sendo realizado? O que é um "sabá"? Quais as diferenças entre a pintura de Goya e os filmes de Harry Potter? Rituais de magia envolvem fé, crença, religião e credo? O movimento Surrealista e o seu universo onírico e utópico possui certa relação com as práticas sociais voltadas para as questões do sobrenatural? Por quê? Práticas de fé e conexão com uma realidade sobrenatural se fazem presentes desde os primórdios da humanidade, assim, quais relações estabelecemos com nossas práticas de fé e nossas atividades cotidianas?

Proposta 01: Construa com os estudantes vídeos a partir dos conceitos de magia e fantasia. Produza, antes, um roteiro idealizando todo o processo de criação. Proponha o uso dos telefones celulares para a realização dos vídeos. Os estudantes poderão usar o cenário da escola, bem como seus espaços ao arredor para realizar as gravações. Poderão convidar colegas, amigos, professores para fazer parte das gravações. Como sugestão, peça para os estudantes fazerem o download em seus telefones dos aplicativos de edição de vídeos gratuitos como: FilmoraGo, Adobe Premiere Clip e o Quik. Exiba todas as produções para que todos possam assistir. Discuta com a turma como os vídeos foram produzidos e como os conceitos de "magia" e "fantasia" se apresentaram em meio às produções. Promova um debate de modo a compreender e refletir com os alunos como tais conceitos e "práticas" influenciaram no processo de construção do trabalho.

Proposta 02: Crie um baralho de "cartas mágicas" com os estudantes. Cada carta poderá ter certa "intenção" e propostas, como por exemplo: Carta 1 - Magia da Solidariedade; Carta 2 - Magia do Respeito. As cartas, também, poderão ser criadas a partir das crenças, fé e religião de cada um dos estudantes, de modo que eles possam vivenciar, em meio a esse processo, aquilo que acreditam. Em seguida, desenvolva "práticas" e reflexões por meio das sugestões apresentadas pelas cartas, discutindo e valorizando o respeito entre as religiões e as diferentes crenças. Explore o desenho, a pintura, diferentes tipos de papéis, canetas e lápis para a confecção das cartas. O trabalho pode ser individual ou em grupos, proporcionado aos estudantes a pesquisa do que é um baraIho (bem como quantas cartas possui, que tipos de baralhos existem, quais informações possui em cada carta, seu formato e qual seu objetivo). Promova discussões em torno das criações juntamente com as imagens apresentadas do personagem Harry Potter, dos registros da caverna de Altamira e da pintura de Goya.

Dicas de Pesquisas: Os desenhos e pinturas do artista Holandês M.C Escher. A xilogravura "Bruxas" de Hans Baldung Grien. A pintura "Círculo Mágico" de John William Waterhouse. Explore o movimento Surrealismo. 


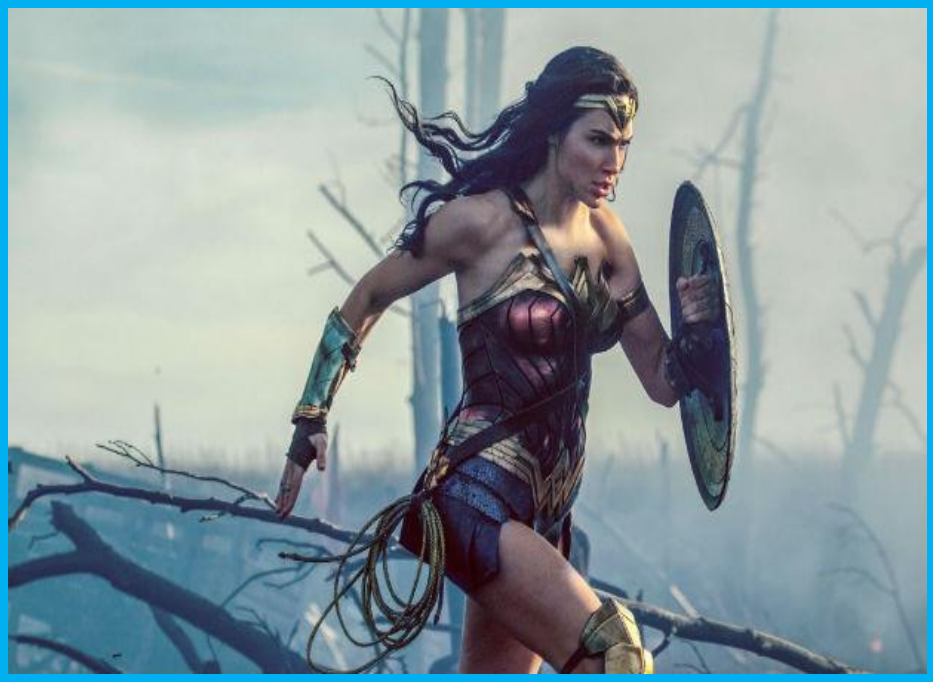

Imagem de Referência: Mulher Maravilha - Personagem de um filme americano de super-herói.

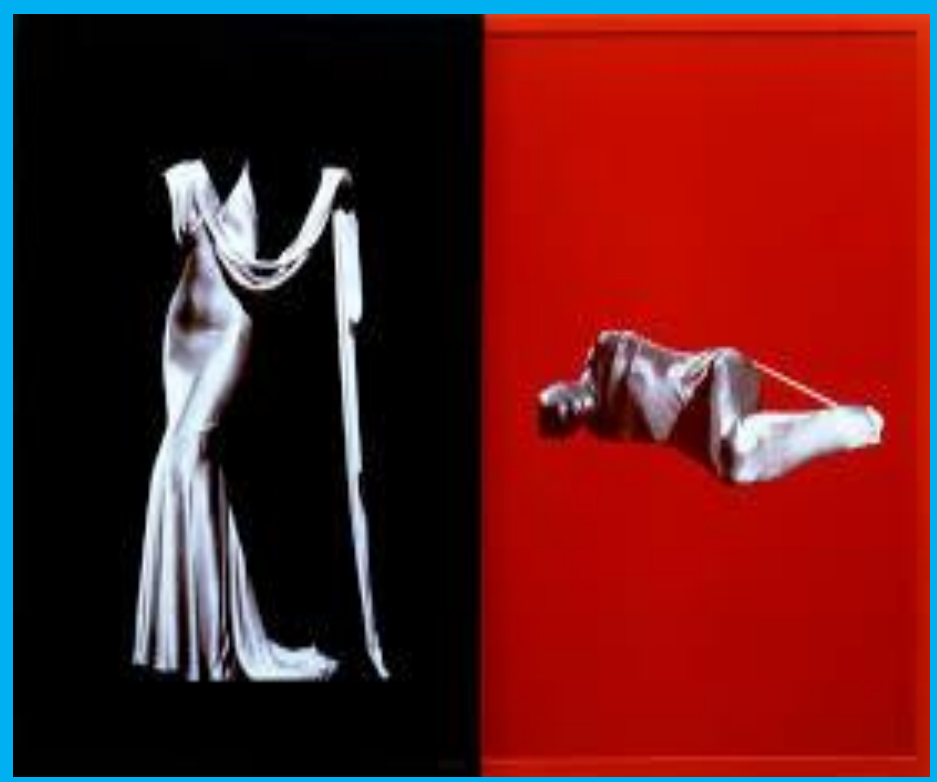

Obra: "Figuras", 1983.

Tamanho: não encontrado. Colagem.

Localizado em: Museu de Arte do Condado de Los Angeles - EUA. Artista: Sarah Charles Worth (1947 - 2013).

Proposta 02: Realize em conjunto com os estudantes um álbum de imagens com diferentes tipos de mulheres (muIheres de diferentes corpos, etnias, idades, religiões, estilos de vidas, nacionalidades, culturas e espaços sociais). Estas imagens poderão ser coletadas de revistas, jornais e de espaços virtuais. Após, a coleta das imagens reúna os estudantes em um círculo para discutir sobre o material coletado. Questione sobre as diferenças culturais, sociais, imposições sociais entre as imagens. Promova um debate em que os estudantes possam perceber que os regimes de "verdades" impostos em relação às mulheres mudam a partir dos espaços em que elas estão inseridas, bem como ao longo da história da humanidade. A construção do álbum poderá ser realizada em um espaço virtual (se todos tiverem acesso), ou manualmente em cadernos, agendas, etc.
Questões Potentes: Qual é a relação de guerra e de violência entre as duas imagens? $\mathrm{O}$ que esconde a imagem do vestido na obra "Figuras"? Qual seria o papel da mulher que na obra de Sarah Worth tenta "libertar"? Como possíve interpretação dos elementos da obra de Sarah Worth como o corpo amarrado e o vestido de noite (com suas marcas impostos pela sociedade) busca uma nova posição do papel mulher na sociedade. Qual seria essa posição? Quais as diferenças entre a roupa de "Mulher Maravilha" e os elementos da obra "Figuras"? Quem é a Mulher Maravilha? A Mulher Maravilha seria uma nova ideia de mulher nos dias atuais, diferentemente da mulher apresentada na obra "Figuras"? Quem são as "Mulheres Maravilhas" do nosso cotidiano? Por que essas mulheres poderiam ser vistas dessa maneira? Elas lutam pelo quê? Em que momento da história a artista Sarah realizou seu trabalho? E de que forma essas duas imagens se relacionam com as nossas vidas? Há, por meio das imagens, alguma referência ao movimento "feminista"? O que esse movimento representa para os nossos dias?

Proposta 01: Realize com os estudantes uma pesquisa fazendo recortes em jornais e revistas sobre palavras/frases/dizeres/pensamentos/ ditos populares machistas e imagens que coloque a figura das mulheres em situação de submissão, inferioridade em relação aos homens e em situações que envolvem o preconceito. Analise tal exercício a partir dos papéis sociais e dos diferentes contextos da mulher na contemporaneidade, bem como as convenções e os regimes de verdades que circulam em torno da mulher. Discuta sobre as conquistas de espaços e direitos que a mulher possui hoje e quais elas deverão ter (relembre o dia 08 de março, "Dia da Mulher"). Após, crie cartazes (no estilo de propagandas) a partir dos recortes e das análises de modo a desenvolver a reflexão, a valorização, o respeito e a conscientização dos novos papéis da mulher nos dias atuais. Explore a colagem, a escrita, o desenho e os diversos materiais. As estratégias da linguagem visual poderão ser exploradas nessa atividade. Como desdobramento, os cartazes poderão ser transformados em cartilhas, podendo ser distribuídas para toda a comunidade escolar.

Dicas de Pesquisas: Pinturas da artista Mexicana Frida Kahlo. O filme "Frida". Os autorretratos da artista Americana Cindy Sherman. As esculturas da artista Francesa Louise Bourgeois. As colagens da artista Brasileira Barbara Kruger As fotografias e instalações da artista Francesa Sophie Calle. As performances da artista Italiana Vanessa Beecroft. As pinturas da artista Inglesa Jenny Saville. As fotografias da artista Holandesa Rineke Dijkstra sobre (maternidade e nascimento). O coletivo Guerrilla Girls. As capas das revistas Vogue e entre outros artefatos culturais. 
Pra quem não botou fé, Pra quem não botou fé

Pra quem não botou fé, Pra quem não botou fé

Pra quem não botou fé, Pra quem não botou fé

Pra quem não botou fé, Pra quem não botou fé

Na night truva nos rolê e o bonde é pesadão

As nave baixa os crente loko hoje eu tô pra missão

Os grave bate a unção desce os meninos tão na rueira

Pra quem não botou fé, nois não chegou pra brincadei-

ra

Tuvou na quina fi, ideia

Colei com os pivetin, ideia

Emabassou rapidin, ideia

Os crente é louco fi, ideia

Louco, loucura, louquira na quebrada rueira

Cristo que manda aqui

Vai fortalecer a ideia sistema me erra

Cristo que manda aqui

Palavra rimada lança pregada

Cristo em todos nos

Santo Espírito que guarda quebrada

Escuta nossa voz

Imagem de referência: Os Pregadores da Paz - Uma banda de música rap.

Música: "Para quem não botou fé” - Fragmento da música.

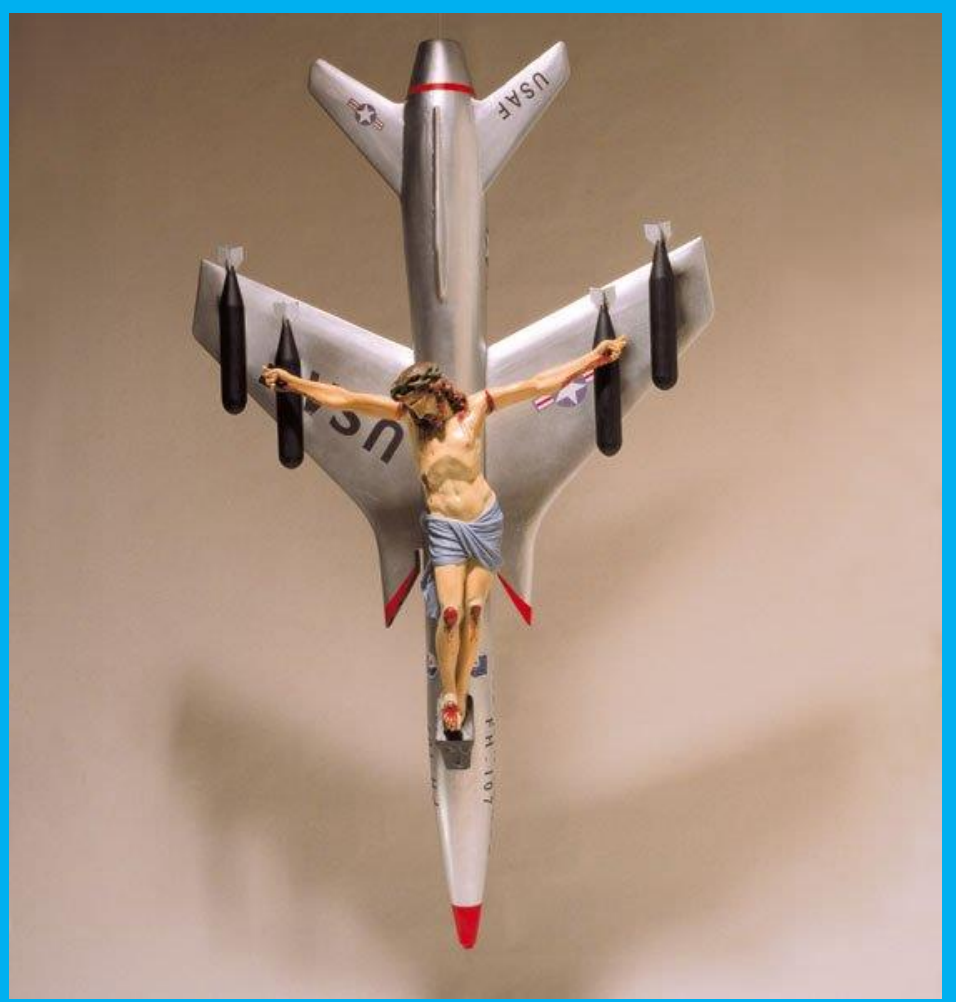

Obra: “A civilização ocidental e cristã", 1966.

Tamanho: Não identificado. Objeto.

Localizada em: Museu de Arte de São Paulo, MASP - Brasil.

Artista: León Ferrari (1920 - 2013).
Questões Potentes: Do que fala o fragmento da letra da música? Qual é a crença religiosa que podemos identificar a partir do fragmento do rap? E quais são as diferenças de crenças religiosas entre a obra de León Ferrari e música dos Pregadores da Paz? Quais seriam as ideias, conceitos, mensagens/ discursos do fragmento da música e sua relação com a obra? O que é fé? O que e religião? Quais os tipos de religiões que existem? O que é intolerância religiosa? Na obra de León Ferrari a fé e a religião se apresentam de que forma? León Ferrari ao colocar a imagem de Cristo pregado em um caça aéreo sobre as bombas faz uma crítica a quê? Qual a relação da obra de Ferrari com a Igreja Cristã? Você se identifica com essa imagem? Por quê?

Proposta 01: Realize uma coleta de objetos, acessórios, roupas, artefatos culturais e utensílios que se identificam com as diferentes religiões e aquilo que os caracterizam. Procure coletar o maior número possível de objetos de diferentes crenças religiosas. Discuta os aspectos culturais, sociais e políticos do material coletado, valorizando as diferenças entre as crenças religiosas de cada um, promovendo o respeito e a tolerância religiosa. Proponha com o material coletado uma intervenção no pátio da escola ou em outro espaço. A intervenção deverá ter uma crítica um questionamento que os estudantes queiram fazer sobre os materiais coletados e as discussões coletadas. Observe e anote as reações e argumentações das pessoas sobre as intervenções.

Proposta 02: A partir das discussões proponha aos estudantes a realização de esculturas a partir de objetos do cotidiano industrializados em série. Peça a eles/as que tragam diferentes objetos à sala de aula que possam ser cortados, colados, amassados, furados, torcidos, etc. Com os diferentes objetos sugira que criem esculturas fazendo alguma crítica que envolva os conceitos estudados como; fé, religião, crença, intolerância religiosa, como fez o artista Ferrari (apresente outras obras do artista como exemplos). Proponha uma discussão sobre a realização das esculturas e os conceitos que envolverem em seus trabalhos.

Dicas de Pesquisas: Videoclipe "Live to Tell" da cantora Madona. As pinturas Renascentistas e Barrocas. O Barroco Brasileiro - Alejadinho. Pinturas Góticas. A arte Bizantina (mosaicos e afrescos). A obra "O Cristo do mijo" de 1987 de Andres Serrano. 


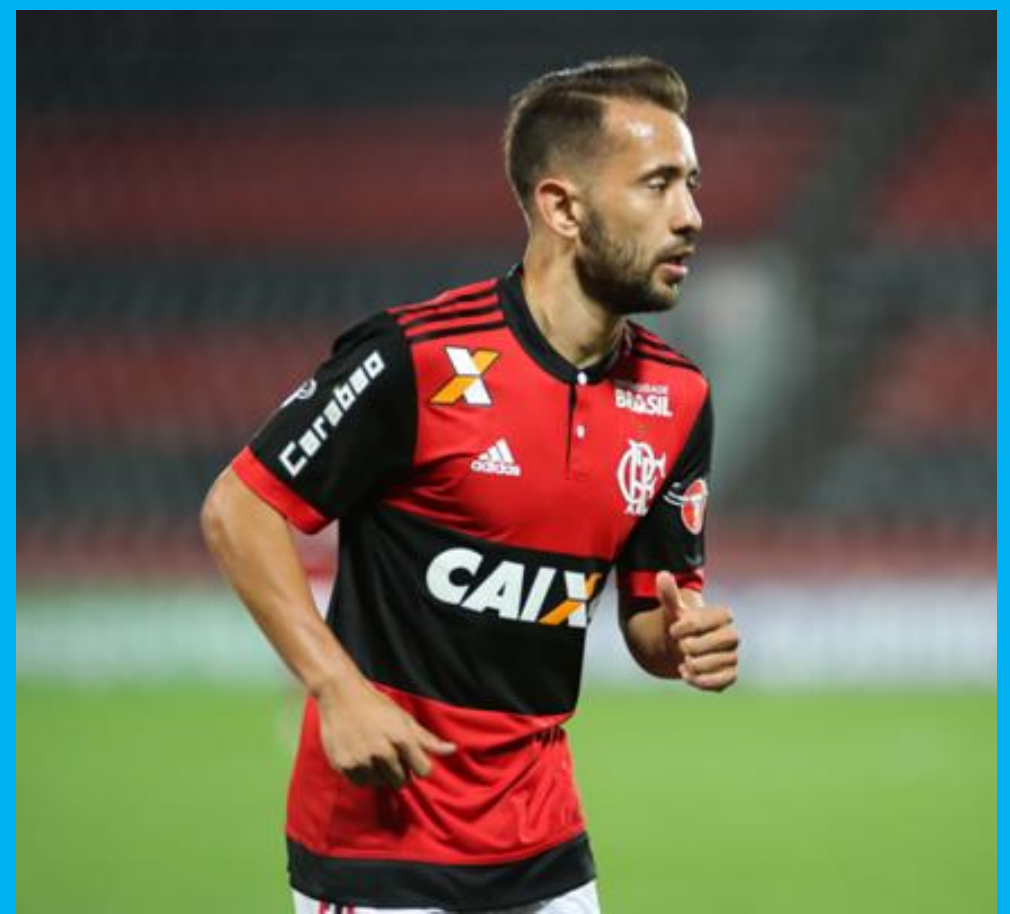

Imagem de referência: Éverton Augusto de Barros Riberio Éverton é um jogador de meio de campo do Flamengo.

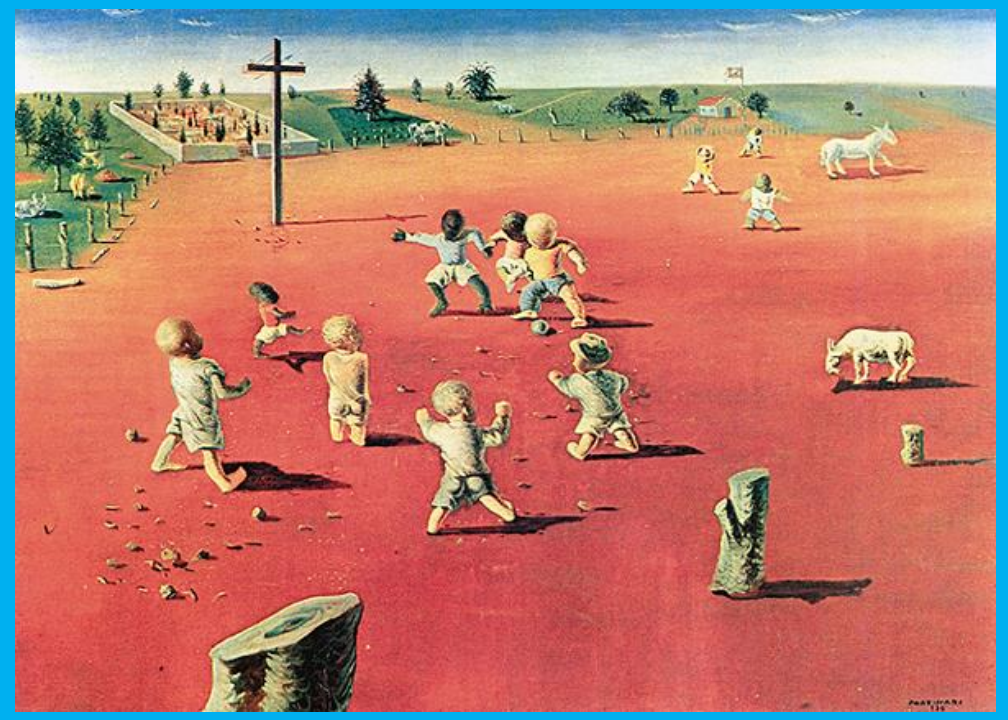

Obra: "Futebol em Brodósqui", 1935.

Tamanho: $97 \mathrm{~cm} \times 1,30 \mathrm{~cm}$, Óleo sobre tela.

Localizada em: Coleção Particular - Rio de Janeiro.

Artista: Cândido Portinari (1903 - 1962).

Dicas de Pesquisas: A pintura "Futebol" de 1936 do artista Francisco Rebolo. As pinturas do artista Brasileiro Orlando Teruz. A obra "Futebol", de 2001 de Nelson Leirner. As pinturas Art Naif Brasileira que tratam bastante a cultura brasileira especialmente as pinturas de Nerival Rodrigues e Valquiria Barros. A obra chinesa "Dama chinesas jogando caju" (chutar a bola), do artista Chinês Du Jin. A pintura "Sunderland vs Aston Villa" de 1895, do artista Inglês Thomas M.M. Hemy (Esta obra conta um pouco das origens do futebol). A pintura "Indo para a Partida" de 1923, de L.S. Lowry. A ilustração "Adidas: Afresco" de 2006, do ilustrador Felix Reidenbach. A obra "Campo Verde" de 2006, do artista Brasileiro Felipe Barbosa realizado com objetos do cotidiano.
Questões Potentes: Quais são as diferenças entre as duas imagens? O que é um esportista? Quais as modalidades de esporte existem? Para que serve um esporte? Por que vocês praticam esporte? Por que os jogos (esportes) e sua relação de competição "surgiram" no Coliseu em Roma? Existem influências dos jogos do Coliseu nos esportes que praticamos nos nossos dias atuais? Quais as semelhanças entre o jogador Éverton e os meninos na pintura de Portinari? Onde acontece o jogo de futebol na pintura de Portinari? Quais as relações destas duas imagens com a História do Brasil? Quais seriam os aspectos e elementos culturais da pintura de Portinari?

Proposta 01: Realize uma pesquisa com os estudantes sobre os times de futebol que existem no Brasil, utilizando os seus telefones celulares. Provoque discussões sobre as pesquisas, conhecendo a histórica de cada time. Desenvolva análises sobre os escudos dos clubes, observando aquilo que os que compõem: formatos, se possuem números, palavras, datas, imagens e cores. Crie a partir das discussões e das análises um projeto de escudo para a sala de aula, ou cada grupo poderá fazer o seu. O escudo poderá ser realizado através de colagem ou "isogravura" ou outras técnicas de acordo com os materiais e as necessidades da escola e dos estudantes. Após, realize discussões sobre o processo, fazendo relações com as imagens.

Proposta 02: Proponha aos estudantes a realização de uma performance chamada "inversão" no espaço escolar. Primeiramente liste todos os objetos que se usam no futebol, as regras do jogo, a quantidade de participantes e o local do jogo, etc. Despois explore a inversão do que os estudantes listaram como, por exemplo: vestir as camisetas do avesso, caminhar/corres para trás, jogar a bola com as mãos, cartão amarelo para quem encostar o pé na bola, dois goleiros no gol ou cada time. Poderá ter dois gol, quinze jogadores ou mais em cada time, etc. Após, discuta com os estudantes como foi fazer a inversão dos objetos/regras/ações, quais foram às dificuldades, facilidades. Explique o que é uma performance (o corpo como suporte artístico), dê exemplo de outras performances. 
Dani Russo \#PPF

Eu não to brigada com minha mãe, nao To com raiva, ela não me trata mal, ela só perdeu a cabeça... E quero passar uma msg pra vocês.

$$
\text { \& } \quad \text { e7 } 34 \bullet 426 \quad \mathbb{}
$$

\section{Dani Russo \#PPF}

Eu não bati nela não, depois da minha briga de escola eu nunca mais na minha vida levanto a mão pra ninguém

Fragmento do seu discurso retirado do seu twitter sobre a violência que sofreu de sua mãe.

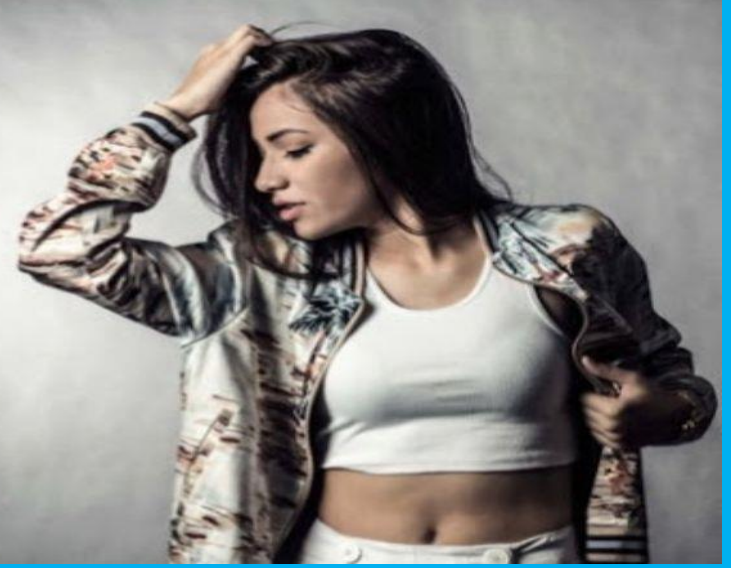

Imagem de referência: Danni Russo - Dani é uma blogueira Youtuber e um humorista Brasileiro.

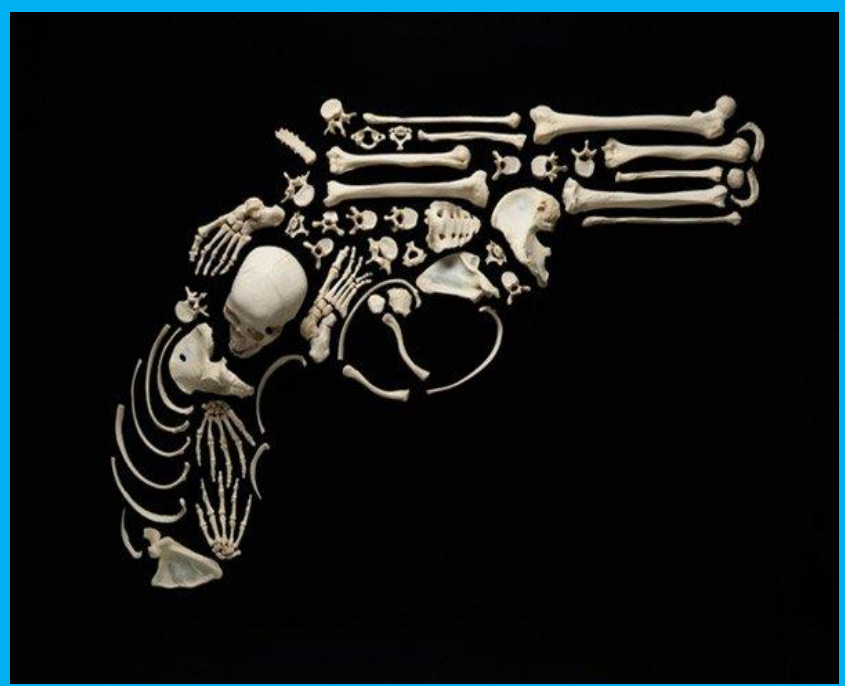

Obra: "Ossos Contra Violência”, faz parte da série de fotografias chamada "Stop the Violence", de 2008.

Tamanho: Não identificado. Fotografia.

Localizada em: Coleção Particular.

Artista: François Robert (vivo).
Questões Potentes: Do que se trata a postagem realizada no twitter da Dani Russo? Podemos identificar que tipo de violência em sua postagem? O que seria um ato violento? Nos meios de comunicações diários e nas redes sociais vocês presenciam quais os tipos de violência? Quais os tipos de violência existem? No convívio familiar ou no espaço social de vocês, quem presencia violência? Quem são as vítimas da violência (mulheres, crianças, idosos, sujeitos não normativos, negros, etc)? Na fotografia do artista François que tipo de violência ele apresenta? A violência apresentada na fotografia do artista faz referência a alguma manifestação? E o quê seria esta manifestação? Os ossos do corpo humano que desenham o revólver faz referência a quê? O Objeto "osso" apresentado na fotografia do artista não seria os mesmos ossos que possuímos em nossos corpos? O objeto revólver faz referência a quê? Qual sua simbologia na sociedade? Quais as possíveis relações entre a postagem da Dani Russo com a fotografia "Ossos Contra Violência"?

Proposta 01: Proponha para os estudantes a criação de uma "Carta Virtual". Após dialogar com os/as estudantes sobre o que é violência, os tipos de violência que existem, e quem sofre violência - considerando seus posicionamentos críticos - peça para os/as estudantes produzirem em grupos ou individualmente uma carta virtual para postar em suas redes sociais, falando sobre um tipo de violência, alertando seus internautas sobre os motivos, causas e soluções para o combate. Peça aos estudantes pesquisarem sobre os tipos de violência como; por exemplo: que são os agressores, quais os países que mais sofrem por causa da violência, quais os estados brasileiros que possuem as maiores incidências, se existem dados qualitativos sobre, se existem programas sociais de combate à violência, os principais motivos, causas e consequências, etc. Para esta atividade os/as alunos/as poderão usar os seus telefones celulares. A carta poderá ser criativa de maneira que todos, nas redes sociais, tenham o interesse de acessar e ler e, talvez, se posicionarem sobre o tema.

Proposta 02: Realize com os estudantes uma pesquisa sobre a violência, guerra, manifestações, etc; em diferentes períodos e momentos, tendo em vista os diferentes contextos dentro da História da Arte. Divida os períodos e as vanguardas entre os/as estudantes, de modo que eles tenham que pesquisar diferentes obras - pinturas, esculturas, gravuras, arquiteturas, desenhos, objetos - que remetem ao assunto. Peça para os/as estudantes que coletem as imagens e faça uma linha do tempo contextualizando tal movimento ou período com suas influências, motivos e consequências. Em seguida, sugira aos alunos que apresentem de maneira criativa suas pesquisas para o restante da turma, discutindo os aspectos da violência, as guerras e as manifestações sociais, bem como os tipos de violência que foram representados por meio da arte ao longo do tempo, estabelecendo possíveis comparações com aquelas que ocorrem nos dias atuais.

Dicas de Pesquisas: A arte Egípcia e Roma possui uma variedade de imagens - esculturas, pinturas, afrescos, pinturas em cerâmicas e utensílios - com cenas de violência. A arquitetura do "Coliseu”, localizado na Roma. A obra "Guernica” de 1973, de Pablo Picasso. As obras conceituais do artista Brasileiro Cildo Meireles: projeto "Inserções no Circuito ideológico". A instalação de Objetos "Armas" de 2008, da artista Gisela Mota. As pinturas - suas obras tratam das guerrilhas Colombianas, tráficos de drogas, ações militares e morte - do artista Colombiano Fernando Botero. As instalações realizadas com lâminas de giletes da artista Brasileira Nazareth Pacheco. As obras do Chinês Yang Shaobin. As aquarelas de Jean Debret pintadas sobre a escravidão no Brasil Colônia. A pintura "Liberdade Guiando o Povo" de 1830, do artista Eugène Delacroix. Diferentes obras da História da Arte que foram tratados sobre este assunto. Pode-se fazer com as disciplinas de História e Literatura. Produções Cinematográficas. 